\title{
Do Gênio da Língua ao Tradutor como Gênio*
}

\author{
(From the Genius of Language to the Translator as Genius)
}

\author{
Márcio SeligmanN-SiLVA \\ (UNICAMP)
}

REsumo: O texto apresenta dois modelos da tradução que caracterizaram o século XVII e XVIII mas que podem ser vistos como paradigmáticos na Teoria da Tradução. 1) $O$ modelo retórico que defende a possibilidade de tradução e enfatiza a adaptação do original ao "gosto" do público de chegada. 2) O modelo que afirma a impossibilidade da tradução, a intraduzibilidade: a) quer porque se valoriza no texto (e sobretudo na escrita dita poética) justamente os seus aspectos mais sensuais e, portanto, indissociáveis da língua de partida; b) quer porque se afirma o relativismo cultural e a intraduzibilidade entre as culturas; c) quer porque se afirma não apenas a impossibilidade de separação entre os significados e os significantes, mas se define o próprio significante e as identidades de um modo geral como sendo um resultado de um jogo diferencial.

PaLAVRas-Chave: Belles infidèlles; Intraduzibilidade; Relativismo cultural; Gênio.

ABSTRACT: The article presents two translation models that were typical in the XVII and XVIII centuries, but can also be seen as paradigmatics in the field of Translation Studies: 1) The rhetorical model that defends the possibility of translation and emphasizes the necessity of adapting the "original" to the "taste" of the target public. 2) The model that affirms the impossibility of translation, the non-translatability: a) because the sensual elements that are linked to the language of the "original" are praised; b) because there is a defense of the cultural relativism and of the non-translatability between cultures; $c$ ) or because there is a defense not only of the impossibility to separate signifiers and meaning, but also because there is a definition of the signifier and of all identities as being the result of a differential game.

KEY-WORDs: Belles infidèlles; Non-translatability; Cultural relativism; Genius.

\footnotetext{
${ }^{*}$ Com poucas alterações, este texto foi apresentado como uma palestra no Instituto de Estudos da Linguagem da UNICAMP em 27.10.1998.
}

D.E.L.T.A., 19:EsPeCIAL, 2003 (175-191) 
É inegável que nas últimas duas décadas a Teoria da Tradução sofreu um boom e aos poucos conseguiu ganhar um espaço impressionante dentro das discussões acadêmicas e também para além desse âmbito. Isso é muito saudável e não pode ser desvinculado das complexas articulações que se dão na era da Glocalização, ou seja, do movimento complementar entre a Globalização (econômica e da circulação de informações) e, por outro lado, a (re)afirmação das culturas locais. Creio, no entanto, que a Teoria da Tradução atual peca algumas vezes por uma visão histórica estreita. É claro que existem exceções - algumas ilustres como George Steiner e Antoine Berman -, mas credito que muitos dos erros cometidos por teóricos da tradução tem sua origem em uma visão de mundo simplista e por demais pragmática. Isso talvez esteja na origem de uma tendência teórica que, partindo de uma leitura um tanto apressada de comentadores de autores ditos desconstrutivistas, defende (de modo quase que fundamentalista...) as identidades, sobretudo quando se trata da defesa dos assim chamados "subalternos" ou "híbridos", ou seja "nós". Essas leituras além de serem profundamente contraditórias ao defenderem ao mesmo tempo uma disseminação da diferance e pregarem a (arque-)identidade das culturas "menores", tendem a misturar resquícios de um marxismo mal resolvido com uma glamourização dos "oprimidos”. Todorov (1999), entre outros, já criticou a crise de "vitimização" pela qual a cultura americana (e americanizada) passa e não preciso insistir aqui nesse ponto. Creio que Derrida não é culpado por esse tipo de apropriação metafísica e ontologizante de suas idéias - ele não tem culpa de ser um filósofo com idéias sofisticadas -, mas também acho que não seria injustificado tentar aqui e ali lançar um olhar sobre a história de nossa disciplina, ou seja, a Teoria da Tradução. Com este trabalho gostaria de enfocar um momento central na história das concepções de tradução apresentando dentro dele dois modelos "clássicos" da teoria da tradução:

1) $\mathrm{O}$ modelo que defende a possibilidade de tradução e enfatiza a adaptação do original ao "gosto" do público de chegada.

2) $\mathrm{O}$ modelo que afirma a impossibilidade da tradução, a intraduzibilidade:

a) quer porque se valoriza no texto (e sobretudo na escrita dita poética) justamente os seus aspectos mais sensuais e, portanto, indissociáveis da língua de partida; 
b) quer porque se afirma o relativismo cultural e a intraduzibilidade entre as culturas;

c) quer porque, como no caso dos românticos alemães Friedrich Schlegel e Novalis, se afirma não apenas a impossibilidade de separação entre os significados e os significantes, mas se define o próprio significante e as identidades de um modo geral como sendo um resultado de um jogo diferencial.

Por uma questão de espaço deixarei aqui este último ponto apenas mencionado (cf. Seligmann-Silva 1999).

1) Séculos XVII e XVIII: As "belles infidèles": Perrot d'Ablancourt e Nicolas Beauzée:

Nos séculos XVII e XVIII a tradução era basicamente concebida como imitação de um original. Essa noção de imitação, no entanto, não é a mesma que possuímos hoje. Ela deve ser pensada no sentido da tradição clássica-renascentista de imitação vinculada ao trabalho de eleição, imitação que embeleza o modelo. Essa imitação é guiada pela Idéia da obra que é projetada em termos platônicos. Dentro da tradição que vem da Antigüidade não existe mimesis sem criação, poiesis. Mas isso não anula o fato do conceito de "original" dessa concepção de tradução ser estanque e ser considerado como possuindo uma "identidade própria", por assim dizer transhistórica. Ou seja, quero dizer que o ato do tradutor que estava vinculado à doutrina artística da emulação não deve ser confundido com a moderna afirmação da "repetição diferente" (Perniola 2000).

Perrot d'Ablancourt (1606-1664) traduz tendo em vista mais o but, o objetivo das obras (sua Idéia - ou aquilo que ele acredita ser essa Idéia), do que as suas palavras. Ele visa imitar a concep̧̧ão, o desenho, mas também quer se igualar e até ultrapassar o original (Bury 1995: 498). Até o século XVIII a doutrina retórica dos cinco momentos da produção da obra literária moldava toda a reflexão e prática literária: refiro-me aos momentos da inventio, dispositio, elocutio, memoria e pronuntiatio. Criação da idéia e do seu "desenho" (sendo que essa "criação" não deve ser pensada, pósromanticamente, como algo necessariamente "novo"), plano de apresenta- 
ção ${ }^{1}$, criação da tessitura - colorida - do texto, memorização do mesmo e, por último, apresentação em público. Esse modelo retórico anula o tempo e o trabalho da diferença: ele acredita que no ato de pronuntiatio o texto com a sua Idéia - seria "restituído" de modo integral. O discurso deve cumprir o seu papel: se se tratar de um discurso de defesa, convencer ao juiz, se tratar de um poema, agradar. No caso das traduções de Perrot d'Ablancourt, o que importa também é a recepção, ou seja, no caso, agradar ao leitor. $\mathrm{Na}$ apresentação do seu Lucien de 1654 ele escreveu:

eu me propus agradar mais do que ser fiel, ou antes, eu achei que a fidelidade nesse ponto consistiria no agrado, sem me distanciar, no entanto, do objetivo e do desenho do meu Autor. (Apud Zuber 1995: 499)

Ser fiel quer dizer manter o mesmo efeito diante da pronuntiatio/leitura do mesmo objeto que o autor apresentou. A linguagem é vista como puro meio que pode ser dissociado do seu "conteúdo". É interessante notar que d'Ablancourt filia-se abertamente ao modelo retórico da tradução como aemulatio que não deixa de ter relação com a prática da cópia "infiel” (realizada pelo commentator em oposição ao copista fiel, o scriptor) na Idade Média que era marcada pelas interpolações daquilo que o copista acreditava ser adequado para "enriquecer" o "original". Seguindo esse preceito, d'Ablancourt escreveu ainda na mesma Remarque sur la traduction:

Em muitas passagens eu traduzi palavra a palavra [princípio "teológico" ou "bíblico" da tradução], ao menos, tanto quanto isso é permitido numa tradução elegante; existem também outras nas quais eu considerei aquilo que deveria ser dito ou o que eu podia dizer ao invés do que havia sido dito, seguindo o exemplo de Virgílio no que ele tomou de Homero e de Técrito. (Apud Zuber 1995: 498)

Aqui o tradutor assume a posição (forte) do auctor medieval.

A tradução também é vista dentro da tradição retórica, na medida em que é descrita como um processo de transplantação de um clima e de um

\footnotetext{
1 Até o século XVIII o desenho era ora identificado com a inventio ora com a dispositio, de qualquer modo ele era sempre diferenciado do momento do colorir, reservado à elocutio, ou seja, o momento de "ornamentar" o discurso com figuras visando a delectatio, o deleite do ouvinte, que move suas paixões (movere) e facilita o seu convencimento. Com relação à história da comparação entre a pintura e a literatura, ou seja à tradição da Ut pictura poesis que afirma a traduzibilidade entre as palavras e as imagens, cf. meu texto de 1998.
} 
"modo de ser" de cada país - com a sua couleur locale - e época para outro clima e modo de ser. Como o que importa é o transporte da "Idéia" da obra, esta deverá trocar "apenas" a sua vestimenta exterior, que deve ser adequada à moda e clima (costume) do país de chegada.

Portanto, eu não me agarro sempre às palavras nem aos pensamentos deste autor; e permanecendo no seu objetivo, eu adequo as coisas ao nosso ar e ao nosso modo (façon). As diversas épocas exigem não apenas palavras mas também pensamentos diferentes; e os Embaixadores possuem o costume de se vestir segundo a moda do país para o qual são enviados, temendo serem ridículos diante daqueles que eles devem agradar. No entanto, isso não é propriamente a tradução; mas isso é melhor que a tradução; e os Antigos não traduziam de outro modo. (Apud Zuber 1995: 498)

Como nota Zuber, a tradução para d'Ablancourt está submetida à uma espécie de "fidelidade ativa, que se manifesta com gestos precisos: a divisão, a dádiva, a troca de presentes” (Zuber 1995: 380). Ele critica o que ele denomina de "supertição judáica" que exige a submissão à "letra e abandona o espírito, [e] que traduz um Autor como os versos de Oráculo ou de uma Sibila". Isso implica mostrar esse autor "apenas pela metade" na medida em que não há uma transposição da sua "eloquência"; isso é o mesmo que se esforçar muito apenas para "desonra-lo e traí-lo; é despojar um homem de boa casa que nós havíamos simulado abrigar na nossa" casa (apud Zuber 1995: 381). Para d'Ablancourt, portanto, a regra de hospitalidade que deve guiar a atividade do tradutor exige uma troca de "dons": o hóspede dá a sua "Idéia", o anfitrião o "tom" e a vestimenta/costume da mesma. ${ }^{2}$ A tradução literal seria apenas um cadáver, enquanto a belle infidèlle seria um corpo vivo, "belo", "leve", "animado". A tradução está submetida ao agradar, ao âmbito que mais tarde seria denominado de estético e que, então, era assimilado ao retórico e poético. O princípio das "belles infidèles" é o da fidelidade apenas ao espírito, e não à letra, daí esse modelo de tradução ter sido comparado na época à metamorfose e, sobretudo, à

\footnotetext{
2 Mas a hospitalidade é um termo que implica uma relação não apenas de trocas de dádivas: existem regras que devem reger essas trocas para evitar que a relação de hospitalidade se transforme numa relação de hostilidade. A semelhança entre esses dois termos possui, como Benveniste o demonstrou, uma explicação etimológica (Benveniste 1995:87). Derrida, em mais de um ensaio (cf. 1996), desdobrou as implicações históricas dessa proximidade tendo em vista uma política da relação com o outro (e da tradução).
} 
metempsicose. ${ }^{3}$ De certo modo poder-se-ia dizer que a tradução da época das belles infidèles representa a essência da tradução (ao menos no sentido mais comum e banal do termo); afinal toda tradução parte de um ideal de uma Über-Setzung (Berman 1986); toda tradução parte da separação entre o significante e o significado, o espírito e a letra. A questão é como ela se relaciona com essa situação metafísica: se a enfrenta, desafia como se fosse uma tarefa (no sentido romântico de Aufgabe, como tarefa infinita, Seligmann-Silva 1999: 45 ss., 64 ss.), submete-se a ela, ou a (de)nega. O que importa para as belles infidèles é a beleza e a clareza do texto, a sua recepção, e não o respeito pelo texto de partida. Seguindo a doutrina retórica que nos alerta para evitar a todo custo os dois vícios mortais do discurso - o taedium e a incompreensão -, o mais "belo" é, nessa doutrina, o "mais claro". Daí o uso de adições, supressões e explicações em meio ao texto. O texto de chegada deve soar "como se o autor tivesse escrito nessa língua”. A diferença entre as línguas é um empecilho menor que deve ser como que "posto de lado". O conteúdo seria o dado universal da linguagem - que os teóricos de então estudavam sob a chave da Gramática. O que muda são as estratégias retóricas/poéticas de "vestimenta" do "conteúdo" e que devem agradar e seduzir os leitores. ${ }^{4}$

O século XVIII não foi de modo algum homogêneo na sua forma de ver a tradução. A tradição das belles indidelles, que vinha do século anterior, não teve uma morte súbita. Nicolas Beauzée (1717-1789) autor do artigo "Traduction, Version" (1765) da Encyclopédie é uma prova. Nesse artigo ele fez uma importante e clássica distinção entre a versão e a tradução:

Parece-me que a versão é mais literal, mais ligada aos procedimentos próprios da língua original e mais submetida nos seus meios à construção analítica; e que a tradução ocupa-se mais com o fundo dos pensamentos, está mais atenta em apresentá-los sob a forma que pode lhes convir na nova língua e mais subordinada nas suas expressões à índole (aos torneios, tours\} e aos idiotismos desta lingua. (Apud Schneiders 1995: 62)

\footnotetext{
3 Como depois Schoppenhauer expressaria no seu Parerga und Paralipomena com relação à tradução: "Jede rechte Übersetzung ist Travestie. Noch schärfer gesprochen, es bleibt die Seele, aber sie wechselt den Leib: die wahre Übersetzung ist Metempsycose." "Toda tradução correta é travesti [no sentido de um discurso paródico]. Dito de modo mais contundente, permanece a alma, mas ela muda de corpo: a verdadeira tradução é metempsicose" (apud Steiner 1975: 267).

4 O elemento patriarcal (falocêntrico) dessa doutrina é evidente. É interessante notar que esse falocentrismo está aliado a uma afirmação da hierarquia entre significado e o significante, espírito e o corpo. A masculinidade do autor/tradutor (fértil) é oposta à docilidade da tradução feminina, bela e - fielmente infiel.
} 
Essa concepção de tradução dá continuidade ao modelo das belles infidèlle e, portanto, ao da Antigüidade. Falando de modo estrito, entre os latinos não havia um limite entre a tradução e a produção original (Seele 1995: 8). Mesmo Cícero traduziu dentro do paradigma da aemulatio. Tanto para Quintiliano como para Sêneca e Plínio, o Jovem, a tradução era vista como um dos exercícios retóricos fundamentais, ao lado da paráfrase de textos em verso (que eram vertidos para a prosa) ou em prosa e da descrição de quadros ou cenas da natureza (Quintiliano: X, 5, 5 e I, 9, 2.). Nesses exercícios o retor sempre tentava superar o original. Uma vez que se partia do pressuposto que o conteúdo se mantinha "igual" nesse processo, assim, no caso da tradução e da paráfrase, poder-se-ia comparar de maneira privilegiada dois modos de enunciação, no seu estilo, escolha das palavras etc. Era freqüente que o tradutor comentasse e corrigisse o texto em meio à tradução. Mas nem por isso deixou de ocorrer na antigüidade romana uma clara distinção entre esses dois modelos de tradução ressaltados por Beauzée - como se lê por exemplo em Cícero, Horácio e Terêncio - a saber, entre a tradução segundo a fórmula verbum-de-verbum ${ }^{5}$ e a segundo a sensu-de-sensu 6 . Devido à doutrina da emulação, houve um evidente predomínio do segundo modelo.

O importante nesse modelo é o efeito final, do qual não se pode separar o valor estético. Ele deve ser visto como uma conseqüência da concepção representacionista da linguagem (e, portanto, do conhecimento) que imperava na doutrina retórica e poética. O tradutor teria um compromisso

5 Jerônimo no séc. IV ao rever a Vetus Latina, uma versão para o latim que havia sido feita a partir da Septuaginta, renega o valor dessa última, questiona que ela tenha sido "inspirada" - nesse ponto indo contra Santo Agostinho - e considera falsa a lenda dos 72 tradutores da biblia. Numa epístola de 395 ele afirmou um princípio de tradução que representa um estágio intermediário entre a concepção dominante na Antigüidade e a do medievo: "Eu não apenas o reconheço como declaro francamente que nas minhas traduções do grego - com exceção das da Escritura Sagrada, na qual já o posicionamento das palavras é um mistério - translado não palavra a palavra, mas, antes, sentido por sentido." (Seele 1995: 9)

6 Cf. Seele 1995: 86. Em Cícero já se podia encontrar um modelo sofisticado que diferencia três tipos de tradução, correlacionadas aos diferentes gêneros do discurso: a tradução filosófica-científica, a retória e a poética. Hans Vermeer (1992: 214 s.) resumiu esses três modi de tradução com as seguintes palavras: “(1) Cicero übersetzt als Rhetor 'funktional' . [... (2) Als 'Dichter' übersetzt Cicero nach römische Gepflogenheit mit dem Skopos, seine Vorlage möglich noch zu übertreffen. (3) Als 'Wissenschaftler' (und dazu zählt ja auch der Philosoph) übersetzt Cicero 'wörtlich', d.h. bei ihm oft genug: 'morphem(at)isch’”. Apesar dessa tipologia, nas traduções de Cícero predominou o modelo da aemulatio. 
apenas com as idéias, às quais ele teria um acesso sem impedimentos - e essa universalidade da compreensão era um dado central da teoria do conhecimento antiga -, a forma seria determinada pela sua situação particular.

Para Beauzée a versão literal deveria ser apenas um momento que antecede à tradução propriamente dita. Mas já nessa versão dever-se-ia destacar os idiotismos da língua original, preencher as elipses, suprimir os pleonasmos e consertar os desvios da "ordem natural" - que para ele eqüivalia à ordem da língua francesa. Quanto a esse ponto, vale lembrar o famoso dito de Rivarol, autor do Discours sur l'universalité de la langue française, de 1784: "Ce qui n’est pas claire, n’est pas français", "o que não é claro, não é francês" (Apud Schneiders 1995: 69). A versão já inicia a reversão ou inversão do "original". Portanto essa versão que ele denomina de "literal" está muito longe de o ser. De resto, a tradução propriamente dita deveria adicionar ao texto da versão o tour e o génie da língua de chegada. O pensamento do original deve ser comunicado como se ele tivesse sido concebido nesse idioma. A tradução deve respeitar - como em d'Ablancourt - o caráter da língua de chegada.

Beauzée foi um teórico da especificidade de cada língua - do seu caráter e gênio - que impõe à versão/tradução o trabalho de reversões. Numa passagem típica das teorias do século XVIII lemos no seu artigo Langue:

O bábito de um povo de empregar de preferência certos sons, ou de flexionar certos órgãos e não outros pode freqüentemente ser um índice do clima e do caráter da nação que é determinado pelo clima em muitos pontos, como o gênio da língua o épelo caráter da nação.

Ou seja: o clima determina o caráter da nação e este, por sua vez, imprime sua marca no gênio da língua. Em um exemplo típico do relativismo cultural de sua época, Beauzée arremata:

O uso habitual de articulações rudes designa um povo selvagem e não policiado. As articulações líquidas são (...) uma marca de nobreza e de delicadeza, tanto nos órgãos como no gosto. 


\section{2) O gênio e a sua intraduzibilidade: Dubos e Charles Batteux}

Jean Baptiste Dubos (1670-1742) é um dos responsáveis no início do século XVIII pela revalorização da linha sensualista (e de certo modo "irracionalista”) da tradição Retórica/ Poética, em oposição ao domínio das doutrinas derivadas do racionalismo do século XVII na linha da Grammaire générale et raisonée de Port-Royal. Com Dubos ocorre uma valorização do elemento sensual da poesia e não mais tanto da inventio. A elocutio que ele denomina de "poesia do estilo", diferentemente do que ocorria até então, passa a constituir o desenho da poesia: ou seja, o desenho não é mais equiparado à Idéia e à inventio. Para ele a "poesia do estilo" - ou seja, a invenção de figuras poéticas - é que faz da poesia uma poesia. Mas se agora o elemento sensual da linguagem é valorizado, a couleur locale como que passa, com mais razão, a controlar o "desenho". A "originalidade" da obra - incluindo a sua relação com o seu local de origem, como vimos em Beauzée um ótimo exemplo também do século XVIII - adquire um novo sentido e ganha muito mais peso.

Para Dubos ${ }^{7}$ só podemos julgar as obras escritas numa língua que nós compreendemos. Não se pode tentar julgar uma obra com base em traduções ou com base no juízo estabelecido pelos críticos e historiadores da literatura. Isso ocorre desse modo justamente pela originalidade da poesia que impõe a ela uma intraduzibilidade. Dubos faz uma série de comparações para tentar ressaltar o "absurdo" da empreitada do julgamento "de segunda mão" (um topos, de resto, que ainda é válido para muitos teóricos da tradução de nossa época). Ele compara esse procedimento à tentativa de explicar as cores a um cego de nascimento, ou às pessoas que seriam citadas para testemunharem sobre um acontecimento que elas não presenciaram. Para ele a tradução tanto da poesia do estilo como do ritmo e da harmonia, é impossível devido à diferença entre as diversas línguas. $\mathrm{O}$ medium da língua é levado em conta; portanto não há mais a possibilidade de se traduzir.

Uma vez que não reencontramos numa tradução as palavras escolbidas pelo autor, nem o arranjo no qual ele as havia posto para agradar ao ouvido e para emocionar o coração, pode-se dizer que julgar de modo geral um poema com base numa versão eqüivale a querer julgar um quadro de um grande mestre, elogiado sobretudo pelo seu colorido, com base numa estampa na

7 O que segue sobre Dubos retoma com algumas nuanças meu trabalho de 1999: $26 \mathrm{~s}$. 
qual o traço do seu desenho ainda estaria corrompido. Um poema perde na sua tradução a harmonia e o número que eu comparo ao colorido de um quadro. Ele perde aí a poesia do estilo que eu comparo ao desenho e à expressão. Uma tradução é uma estampa na qual nada permanece do quadro original a não ser a ordem e a atitude das figuras: por mais que ela esteja alterada. (Dubos 1770: 2a parte, 556)

\section{Citemos também:}

É da essência de toda tradução verter tão mau as maiores belezas de um poema na mesma medida em que ela verte fielmente os defeitos do plano e dos caracteres. Se é permitido falar desse modo, na poesia o mérito das coisas está quase sempre identificado com o mérito da expressão. (Dubos 1770: 2a . parte, 553)

O significado não existe sem o significante - ao menos na poesia.

Isso também valeu para Condillac no seu Essai sur l'origine des connaissances bumaines:

Entre todos os Escritores é entre os Poetas que o gênio das Línguas se exprime do modo mais vivo. Daí a dificuldade em traduzi-los: ela é tal que, com talento, seria mais fácil de superá-los com freqüência a nos igualar-mos a eles sempre. A rigor poder-se-ia mesmo dizer que é impossivel realizar boas traduções: pois as razões que provam que duas Linguas não poderiam possuir o mesmo caráter, provam que os mesmos pensamentos raramente podem ser restituídos numa e noutra com as mesmas belezas. (Condillac 1746 apud Meyer 1965: 166) ${ }^{8}$

John Locke, de resto, já insistira nessa não correspondência entre as línguas de que Dubos parte. Isso pode ser visto como um desdobramento da sua teoria da origem arbitrária da linguagem. ${ }^{9}$

A reflexão sobre a diferença do genius (do indogermânico gen, criar, dar a luz; gr. génesis: origem) de cada "nação" também pode ser retraçada à

8 Cf. também Diderot na sua Lettre sur les sourds et muets (71 s.): "Je croyois avec tout le monde, qu'un poëte pouvoit être traduit par un autre: c'est un erreur, \& me voilà désabusé. On rendra la pensée, on aura peut-être le bonheur de trouver l'équivalent d'une expression; [...] c'est quelque chose, mais ce n'est pas tout. L'emblême délié, l'hiéroglyphe subtil qui regne dans une description entiere, \& qui depend de la distribution des longues \& des bréves dans les langues à quantité marquée, \& de la distribution des voyelles entre les consonnes dans les mots de toute langue, tout cela disparoît nécessairement dans la meilleure traduction."

9 Cf. em An Essay concerning Human Understanding (1689) de John Locke o capítulo V, "Of the Names of mixed Modes and Relations" (1975: 432s.). 
tradição Retórica clássica. Quintiliano, por exemplo, descreve o genus Rhodium, que constituiria um terceiro estilo, além do ático e do asiático, como um gênero misto que teve a sua origem em Aeschines quando ele levou a cultura ateniense para Rodes. Nessa trans-posição teria ocorrido, como explica Quintiliano, uma “degeneração”. (Quintiliano: XII, 9, 19)

O genius serve tanto para descrever o traço individual do estilo (de stilus, caneta, i.e. caligrafia, traço próprio) de um gênero literário, uma época ou região, como a comunidade com as suas características próprias culturais e naturais - assim pode-se falar de genius de uma língua. Nesse gênio da língua concentram-se todos os elementos - retóricos ou estéticos - que transcendem à gramática e não são redutíveis ao racional. (Schneiders 1995: 76) ${ }^{10}$

Em Dubos, acrescenta-se ainda a categoria do artista como gênio desenvolvida a partir da noção retórica, também presente em Quintilano, de ingenium, que constituiria um terceiro grau de intraduzibilidade que estaria na base da produção poética. Essa categoria de gênio, que foi central nas Poéticas do século XVIII desdobra a noção clássica do estilo como um "não sei quê". O Ingenium é traduzido para o francês tanto por esprit (Boileau na sua Arte poética I 166) como por génie (Buffon) e significa o talento natural que não pode ser atingido nem pela imitação - a imitatio nem através da ars. (Lausberg 1990: § 1152) Já para Du Bellay (1522-1560) a tradução era algo intrinsecamente instrumental, "bassement utilitaire". Estava distante do ofício do verdadeiro poeta, que deveria compor na langage de Dieu. Para ele “'l'élocution' est essentiellement

10 No século XVIII a noção de propriedade original sofre uma mudança radical com o surgimento do relativismo histórico em autores como Dubos, Condillac, Rousseau, Diderot, Herder etc. No século XIX esse relativismo deu lugar ao historicismo com a sua afirmação radical da diferença (ontológica) entre as culturas/nações e, por outro lado, foi somado à explicação científica para a origem das espécies e à fundação da ciência da origem, a saber, a genética, com Mendel tendo decifrado a lei da hereditariedade em 1866. No final do século XX a definição da nossa "originalidade" sofre uma nova virada radical com uma noção de génesis da identidade (cultural e/ou nacional) sendo definita agora tanto em termos antropológicos como biológicos herdados do século XIX só que agora servindo como principal nível de articulação das identidades após a crise do Estadonação e das grandes narrativas universalizantes. Na linha oposta dessa doutrina da origem, o desconstrutivismo representa o lado da tradição romântica que não triunfou no século XIX, ou seja, aquele que vai a contra-pelo da afirmação da "origem pura" e que foi formulado por Friedrich Schlegel e Novalis entre os anos 1797 e 1800. 
intraduisible", "a elocução é essencialmente intraduzível"11, e os tradutores não poderiam representar "ceste energie, et ne sçay quel esprit qui est en leurs escrits [ceux des Anciens], que les latins appeloient genius", "essa energia e não sei que espírito que existe em seus escritos [dos Antigos], que os latinos chamavam genius" (apud Zuber 1995: 23).

Em Charles Batteux (1713-1780) pode-se ler o credo de larga aceitação no Iluminismo acerca do caráter arbitrário da linguagem. Apesar de Locke ter afirmado a diferença entre as línguas partindo desse mesmo pressuposto, não pode-se dizer que existe uma relação necessária entre essa concepção e a afirmação ou negação da traduzibilidade. Para Batteux, no entanto, esse fato estaria sim na base da diferença entre as diversas línguas. Daí porque na sua teoria da tradução ele afirma que não é tanto a passagem do "sens", sentido, de uma língua para outra mas sim que "la vivacité du sentiment cause beaucoup plus d'embarras au traducteur", "a vivacidade do sentimento causa muito embaraço para o tradutor" (Batteux 1774: 280 s.). Batteux, que era tradutor de Epicuro, Aristóteles, Denis de Halicarnasso e Horácio, valorizou a tradução como poucos na sua época: “[...] on sait qu'il faut souvent plus de temps, de peine, d'application pour bien copier un beau tableau, qu'il n'en a fallu pour le faire. [...] il est evident qu'il faut, sinon autant de génie, du moins autant de goût, pour bien traduire, que pour composer", "[...] sabemos que muitas vezes é necessário mais tempo, trabalho, aplicação para copiar bem um quadro do que foi necessário para fazê-lo. [...] é evidente que é necessário, se não tanto gênio, ao menos tanto gosto, para se traduzir bem, do que para

\footnotetext{
11 Zuber 1995: 23. O humanista Etienne Paquier, cuja atividade tradutória o teria "rendu sceptique envers cette activité" (Zuber 1995: 174), também era um crítico da tradução e defensor da obra original na sua peculiaridade e estilo em detrimento da obra traduzida. Nas suas cartas pode-se ler de modo claro as suas opiniões a respeito do tema: "Le traducteur comme un sclave, s'alambique tous les esprits à suivre à la trace les pas de l'autheur qu'il translate, il y consomme son aage, \& y desploye tous les plus beaux traits qu'il pense avoir cours entre les siens, pour se conformer de plus près au naif de l'autre. Cependant petit à petit sa langue maternelle se change de telle façon avec les temps, que comme si nous avions baillé une robe neufve, nous ne voulons plus user de la vieille [...]" (apud Kloepfer 1967: 41). Ou seja, a relação que existe entre a língua e o original e a língua e uma tradução são opostas, na medida em que no primeiro essa relação seria "natural", e no segundo caso se daria como a relação da roupa com o corpo. Em W. Benjamin - no seu "Die Aufgabe des Übersetzers", "A tarefa/desistência do tradutor" de 1921 e publicado em 1923 também nota-se essa separação metafísica, quando ele fala da diferença da relação entre o Gehalt (teor) com a Sprache (língua) no original e na tradução.
} 
compor" (Batteux 1774: 258, 260). ${ }^{12}$ Do ponto de vista da teoria hermenêutica tal como ela se cristalizaria dali a cinqüenta anos, essa equação não expressa nada mais do que o famoso topos schleirmacheriano do intérprete como aquele que deve compreender melhor o texto que o seu próprio autor. (Em outras palavras: esse modelo hermenêutico é na verdade uma transformação de um princípio já existente na tradição retórica.) Não fosse uma posição como que intermediária entre os partidários da tradução e da intraduzibilidade, a teoria da tradução que Batteux sustentou não representa nenhuma grande inovação com relação aos matizes já apontados nas teorias vistas acima no que tange à descrição da mecânica dessa atividade. Novamente reencontramos a exigência da máxima fidelidade ao original - ao modelo da imitação - aliada a uma máxima preocupação com a clarté, clareza, com o agrément, agradar, e com a vivacité, vivacidade, do texto na linguagem de chegada. Para conseguir esse objetivo, o tradutor deve, como em Cícero, "pesar as expressões" para tentar gerar um equilíbrio. Numa metáfora monetária, que explicita a sua visão da linguagem, Batteux esclarece: "Il [sc. le traduteur] ne fera que ce que fait le voyageur, qui pour la comodité donne tantôt une piece d'or pour plusieurs pieces d'argent, tantôt plusierurs pieces d'argent pour une d'or", "ele [sc. o tradutor] não fará nada diverso do que o viajante, que por comodidade dá ora uma peça de ouro em troca de muitas peças de prata, ora muitas peças de prata por uma de ouro" (Batteux 1774: 278 s.). ${ }^{13}$ Mas para Batteux também "il y a dans tous les langues des manieres de parler qui ne peuvent se traduire", "existe em todas as línguas maneiras de falar que não podem ser traduzidas", bem como uma diferença de dignidade entre as palavras nas diversas línguas, que impede a tradução "palavra a palavra" (Batteux 1774: 284 s.). ${ }^{14}$ Batteux retoma então os dois modelos da tradução: uma que é vista como fiel no sentido de ser uma cópia

12 Cf. nesse mesmo sentido as afirmações de Marmontel e de Bitaubé citadas por Lieven D'Hulst (sem data: 52 e 61).

13 Batteux afirma que o tradutor deve tentar manter do original: "l'ordre des choses", "l'ordre des idées", "les périodes", "toutes les conjoinctions", "les phrases symétriques seront rendues avec leur symétrie ou en équivalent" (no que tange tanto ao som como à quantidade e terminação), "les figures du pensée" e os provérbios que devem ser traduzidos por outros provérbios equivalentes (Batteux 1774: 269-279).

14 Cf. quanto a essa diferença a defesa que Batteux fez da "ordem natural" na língua latina e grega - que seguiria a ordem das idéias e da ênfase que se quer dar, devido à sua maior liberdade na organização das frases -, que ele opôs ao francês. Cf. Batteux 1774: 321, 388, bem como o seu Traité de l'arrangement des mots, 1788: 203ss. 
idêntica ao original, e a outra como uma aproximação, um meio de se poder compreender o sentido do original. Esse segundo modelo de tradução - no qual se perde a cor da poesia - Batteux também aproxima da arte da estampa:

Eu distingo aqui dois tipos de tradução: o primeiro é aquele que restitui um autor com tal perfeição que poderia tomar o seu lugar quase como uma cópia de quadro feita por uma excelente mão ocupa o lugar do original. O segundo não é feito para ocupar o lugar do autor, mas para auxiliar apenas a compreender o seu sentido; para preparar as vias para a compreensão do leitor. Seria algo como uma estampa. (Batteux 1774: 289 s.)

Para o autor o primeiro modelo é impossivel para "os poetas". Nesse ponto a pintura estaria em vantagem com relação à poesia, ao menos no que concerne à sua tradução. Pois ao pintor "il ne lui faut que des yeux intelligents \& une bonne main", "basta a ele olhos inteligentes e uma boa mão", para poder reproduzir as cores do original. Mesmo a tentativa de se traduzir um poema em prosa está fadada, para Batteux, ao fracasso. Ele também descarta a paráfrase como meio de tradução; nesse caso, para ele "ce n'est plus traduire, c'est commenter", "não é mais traduzir, é comentar", ou seja, a tradução ideal deveria tentar manter-se dentro do paradigma da mimesis: a interpretação pertenceria a um outro registro. O ideal da tradução - um ideal pictórico - é descartado para ele como um ideal impossível de ser alcançado. A tradução é em si uma empresa sempre condenada ao fracasso. A originalidade da teoria da tradução de Batteux está justamente nessa (re)afirmação da impossibilidade da tradução. Esse topos da intraduzibilidade já havia sido defendido, ente outros, por Dubos e pela Pléiade. Dentro dele a linguagem não pode existir sem a sua cor.

$* * *$

Para os autores aqui enfocados a intraduzibilidade, em suma, originase (Schneiders 1995: 84):

a) de motivos lingüísticos (fonéticos, do campo semântico do vocabulário $^{15}$, de expressões lingüísticas, da sintaxe)

15 Para Dubos não existe justamente uma correspondência exata entre as línguas, ou uma sinonímia. Ele dá alguns exemplos: herus, que implica em latim um maître apenas no sentido de uma relação com um escravo, não poderia ser vertido apenas por maître; hospes, que possuiria originalmente uma 
b) de motivos externos à língua (clima, Estado e Sociedade, ambiente físico).

c) da relação indissociável entre a palavra e o pensamento.

d) e, eu acrescento ainda, da intraduzibilidade de elementos estéticos. Como Diderot afirmou no seu Salon de 1767: não se pode traduzir a originalidade.

Para Johann David Michaelis (1717-1791), no seu De l'influence des opinions sur le langage et du langage sur les opinions, de 1762 (na verdade uma auto-tradução com acréscimos do original alemão de 1760) lemos, por fim:

Todos os objetos apresentam-se ao nosso espírito sob um certo aspecto; e é sob esse aspecto que sempre são regrados os nomes que nós damos a eles e as descrições que nós deles fazemos. (Michaelis 1762: 7)

São as opiniões do povo e o ponto de vista sob o qual ele observa os objetos que dão forma à linguagem. (Michaelis 1762: 9)

Essas palavras de Michaelis já deixam entrever a "virada copernicana" do conhecimento que significou também a sua virada lingüística. Wilhelm von Humboldt (1767-1835) com o seu conceito de "forma interna das línguas" desenvolvido no início do século seguinte já estava montando seus prédios conceituais com uma matéria prima muito parecida com a nossa. Essa "forma interna" significava para ele o resíduo - intraduzível de cada língua, o que escapa ao conceito, e que ao mesmo tempo a constitui (Seligmann-Silva 1999: 26 ss.). A máxima ainda defendida em 1777 por Marmontel, "Le premier et le plus indispensable des devoirs du traducteur est de rendre la pensée; et les ouvrages que ne sont que pensés sont aisés à traduire dans toutes les langues", "O primeiro e mais indispensável dos deveres do tradutor é o de apresentar o pensamento; e as obras que não são senão pensamentos são fáceis de traduzir em todas as língua" (apud D’Hulst s.d.: 49) não pôde mais ser aceita após essa virada copernicana. O discurso que é "só pensamento" também é constituído

dignidade já que implica uma relação de amizade de um homem com outro, não poderia ser traduzido por Hôte (que também conota uma relação comercial); Imperator não deve ser vertido por Empereur, pois não são palavras sinônimas. Dubos inclusive elogia o tradutor que traz para a língua de chegada o termo original intraduzível. 
pela "forma interna", também é ligado por aquilo que alguns autores hoje em dia denominariam de estilo (Frank 1992). O tradutor que agora assume a questão da diferença das línguas será não mais o commentator ou o auctor, no sentido medieval desses termos, mas sim o autor no sentido romântico e pós-romântico (por mais que ele alie o trabalho de tradução ao do comentário e da crítica). Não por acaso esse momento de nova inflexão na história das idéias da tradução coincide com o fim da querelle des anciens et des modernes, o longo debate que ocupou todo século XVIII europeu em torno do estatuto do modelo - exemplar, digno de imitação - da Antigüidade. Sem a presença forte de uma idéia de modelo a tradução teve de ser assumida cada vez mais como forma. Forma formante - lembremos da noção de Bildung - de culturas e literaturas, mas também jogo infinito entre as línguas e suas diferenças.

E-mail: m.seligmann@uol.com.br Recebido em fevereiro de 2002

\section{REFERÊNCIAS BibLIOGRÁFICAS}

Batteux, Charles. 1774. Traité De la Construction oratoire. In: Principes de la Littérature. $5^{a}$ edição. Paris.

1788. Traité de l'arrangement des mots. Traduit du grec de Denys d'Halicarnasse avec des Réflexions sur la Langue Françoise, comparé avec la Langue Grecque, (...) Paris.

Benveniste, Èmile. 1995. O Vocábulário das Instituições Indo-européias. Volume I: Economia, Parentesco, Sociedade. Trad. D. Bottmann. Campinas: Editora da UNICAMP.

Berman, Antoine. 1986. L'essence platonicienne de la traduction. Revue d'esthétique 12: 63-73.

Bury, Emmanuel. 1995. Traduction et classicisme. In Roger Zuber. Les "Belles Infidèles" et la formation du goût classique. Perrot d'Ablancourt et Guez de Balzac. Paris: Albin Michel.

D'Hulst, Lieven (org.) Sem data. Cent ans de théorie française de la traduction. De Batteux à Littré (1748-1847). Lille.

Diderot, 1965. Lettre sur les surds et muets à l'usage de ceux qui entendent et qui parlent. Diderot Studies VII. Otis Fellows (ed.) Genève: Librairie Droz.

Derrida, J. 1996. Le monolinguisme de l'autre, ou la prothèse d'origine. Paris: Galilée. 
Dubos, Jean Baptiste. 1770. Réflexions critiques sur la Poësie et sur la Peinture (1719). $7^{\text {a }}$ edição. Paris.

Frank, Manfred. 1992. Stil in der Philosophie. Stuttgart: Reclam. KLOePfer, Rolf. 1967. Die Theorie der literarischen Übersetzung, München.

Lausberg, Heinrich. 1990. Handbuch der literarischen Rhetorik. $3^{\text {a }}$ ed. Stuttgart: Franz Steiner Verlag.

Locke, John. 1975. An Essay concerning Human Understanding (1689). Oxford.

Meyer, Hugo, 1965. Préface. In: Diderot. Lettre sur les surds et muets à l'usage de ceux qui entendent et qui parlent. Diderot Studies VII. Otis Fellows (ed.) Genève: Librairie Droz.

Michaelis, Johann David. 1762. De l'influence des opinions sur le langage et du langage sur les opinions. Bremen: George Louis Förster (Edição fac-similar: Stuttgart/Bad Cannstaatt: Friedrich Frommann Verlag, 1974).

Perniola, Mario. 2000. Pensando o Ritual: Sexualidade, Morte, Mundo. Trad. Maria do Rosário Toschi. São Paulo: Studio Nobel.

Quintiliano. 1993. Institutio Oratoria. Trad. de H.E. Butler. Cambridge/ London: Harvard University Press.

Schneiders, Hans-Wolfgang. 1995. Die Ambivalenz des Fremden. Übersetzungstheorie im Zeitalter der Aufklärungf (Frankreich und Italien). Bonn: Romanischer Verlag.

Seele, Astrid. 1995. Römische Übersetzer, Nöte, Freibeiten, Absichten. Darmstadt: Wissenschaftliche Buchgesellschaft.

Seligmann-Silva, Márcio. 1998. Introdução/Intradução. Mimesis, tradução, Enárgeia e a Tradição da ut pictura poesis. In: G.E. Lessing. Laocoonte. Ou sobre as Fronteiras da Poesia e da Pintura. Tradução e notas Márcio Seligmann-Silva. São Paulo: Iluminuras/Secretaria de Estado da Cultura: 7-72.

1999. Ler o Livro do Mundo. Walter Benjamin: romantismo e crítica poética. São Paulo: Iluminuras/FAPESP.

SteINER, George. 1975. After Babel. Aspects of language and translation. New York/London.

Todorov, Tzvetan. 1999. O homem desenraizado. Tradução Christina Cabo. Rio de Janeiro: Record.

Vermeer, Hans. 1992. Skizzen zu einer Geschichte der Translation. Frankfurt a.M.

Zuber, Roger, 1995. Les "Belles Infidèles" et la formation du goût classique. Perrot d'Ablancourt et Guez de Balzac. Paris: Albin Michel. 